\title{
A RARE CASE OF AN ISOLATED SUBCUTANEOUS HYDATID CYST IN THE GLUTEAL REGION
}

\author{
Girish Kullolli ${ }^{1}$, Deepak R. Chavan², Shailesh Kannur ${ }^{3}$, Bharat Shankar ${ }^{4}$, Sachin Kadlewad ${ }^{5}$
}

\section{HOW TO CITE THIS ARTICLE:}

Girish Kullolli, Deepak R. Chavan, Shailesh Kannur, Bharat Shankar, Sachin Kadlewad. "A Rare Case of an Isolated Subcutaneous Hydatid Cyst in the Gluteal Region". Journal of Evolution of Medical and Dental Sciences 2014; Vol. 3, Issue 19, May 12; Page: 5276-5278, DOI: 10.14260/jemds/2014/2587

\begin{abstract}
In a tropical country like India, it is not rare to see patients with parasitic cysts. Hydatid cysts most often caused by the parasite Ecchinococcus granulosus present as space occupying lesions of the lung or liver. Isolated musculoskeletal and subcutaneous Hydatid cysts in the absence of any involvement of the lungs and liver are very rare and only a handful of cases have been reported in literature. We report an interesting case of an isolated subcutaneous Hydatid cyst of the gluteal region presenting as a gluteal abscess in a 45 year old lady. This report aims to highlight the unique presentation of the spectrum of Hydatid disease.
\end{abstract}

KEYWORDS: Hydatid Cyst, Subcutaneous Echinococcosis, Gluteal Abscess.

INTRODUCTION: Hydatid disease is a zoonotic disease caused by the parasites of the Echinococcus family. Omnivores such as dogs, wolves and foxes are definitive hosts while humans and other herbivores such as cattle are intermediate hosts. Human infestation is most often through the fecooral route. Hydatid disease often manifests as slowly growing cystic masses. The most common organs involved include the liver and the lungs with various studies reporting incidence rates between 70 to $78 \% .^{1-2}$ The remainder of the cases are accounted by cysts in the muscle, peritoneum, bone, spleen, pancreas, kidney, or even brain. Most of these patients also have concomitant hepatic and pulmonary involvement. Musculoskeletal and subcutaneous hydatidosis is very rare and represents $1 \%-5.4 \%$ of all Hydatid disease. We report a rare case of isolated subcutaneous Hydatid cyst of the gluteal region in a 45 year old lady.

CASE REPORT: A 45 year old lady presented to our hospital with a swelling in the left gluteal region since 1 month. The swelling was initially small and had gradually increased in size. There was no history of pain, discharge or fever. There was no history of any previous intramuscular injections. Patient had received over the counter drugs for the last one week; however the swelling had not decreased in size. Her general physical examination was unremarkable. On local examination, a mildly tender solitary spherical swelling situated in the upper and outer quadrant of the left gluteal region measuring $5 \mathrm{~cm}$ in diameter, with a smooth surface and cystic consistency was noted. Skin over the swelling was normal.

There was no local rise of temperature. All routine laboratory investigations including a complete blood count, differential leucocyte count, urine analysis, renal profile and a chest radiograph were found to be within normal limits. A soft tissue Ultrasonography was performed which revealed a rounded cystic mass that was limited to the subcutaneous plane, superficial to gluteal muscles on left side. The cystic mass contained fluid and showed no flow on Doppler. A Provisional diagnosis of resolving gluteal abscess secondary to folliculitis or antibioma was made and the patient posted for incision and drainage under spinal anesthesia. A cruciate incision was taken 
over the maximum site of pointing. However on surgical exploration, there was a white cystic mass attached to the subcutaneous adipose tissue but free from underlying muscles.

The macroscopic appearance appeared to be that of a Hydatid cyst. It contained non purulent thin serous fluid which was suctioned out. The cyst wall was excised in toto and sent for histopathology. The resultant cavity was washed with Hypertonic saline and left open to heal by secondary intention. The post-operative period was uneventful and the patient recovered well. The HPE showed fibrosis, necrosis, mixed type of inflammatory cells, fibroblastic activity and vascular proliferations in adipose and connective tissues.

A Pericystic structure which consisted of connective tissue and scattered hyaline cells showed a necrotic basophilic structure which resembled cuticular membrane. Scolices were also detected within the surgical specimen.

Patient was started on oral Albendazole for 6 weeks. Patient was screened for liver cysts by abdominal ultrasonography which was normal. The patient was followed up for two years and did not develop any recurrences.

DISCUSSION: The incidence of musculoskeletal echinococcosis including involvement of subcutaneous tissue is $2.3 \%$ of all cases of hydatidosis reported from endemic areas. ${ }^{3}$ The mechanism of the primary subcutaneous localization is unclear. For subcutaneous localization to occur the ova must pass through the liver (first filter) and reach the lung (second filter) and then spill into the systemic circulation, causing Hydatid disease in other organs. Lymphatic spread is also a possibility, with ova migrating into the intestinal lymphatics after the intestinal phase. These ova need favorable environment to seed and grow into large cysts. Muscles with good vascularity and lesser lactic acid are better than other areas.

The Clinical course is non-specific and depends on the site of involvement, the size of the cyst, and the pressure caused by the enlarged cyst. Radiological imaging with ultrasonography, computed tomography, and MRI is useful in rendering the diagnosis, showing the size, localization, relationship to adjacent organs, and type of the cyst. Lewall classified hydatid cysts into three types according to their imaging appearance. Type I is a fluid-filled cyst-like structure, which may proceed to a type II lesion if daughter cysts and/or matrix develop. Type III is a mummified, inert calcified lesion. ${ }^{4}$

The Best treatment option is complete surgical excision of the intact cyst, which avoids leakage of cyst content that can cause anaphylaxis and local recurrence.

The fluid of E. granulosus cysts are rich in antigenic proteins which can trigger anaphylactic reactions. Cyst rupture not only causes anaphylactic shock but may release a large number of viable scolices that implant elsewhere and produce secondary cysts. ${ }^{5}$

Our case report highlights the unique presentation of isolated subcutaneous hydatid cysts with secondary infection. Infected subcutaneous hydatid cysts mimic abscess and may easily mislead the surgeon to perform incision and drainage with the potential to cause systemic dissemination and anaphylaxis. A very high index of suspicion is required in endemic areas to consider the possibility of hydatid cysts in subcutaneous plane.

\section{REFERENCES:}

1. Amir-Jahed AK, Fardin R, Farzad A, Bakshandeh K. Clinical echinococcosis. Ann Surg 975; 182:541-546. 


\section{CASE REPORT}

2. Saidi F, 1976. Surgery of Hydatid Disease. London: WB Saunders Co., 31-59.

3. Munoz Sanz A, ldefonso JA, Saenz Do Santamaria FJ. Hidatidosis detejido cellular subcutaneo. Med Clln (Barc) i985:51:645

4. Lewall DB. Hydatid disease: biology, pathology, imaging and classification (review). Clin Radiol1998; 53: 863-74.

5. Andres Combalia, Sergi Sastre-Solsona (2005) Hydatid cyst of gluteus muscle. Two cases. Review of the literature. Joint Bone Spine (Impact Factor: 2.75). 11/2005; 72(5):430-2. DOI: 10.1016/ j.jbspin. 2004.11.007. Source: PubMed

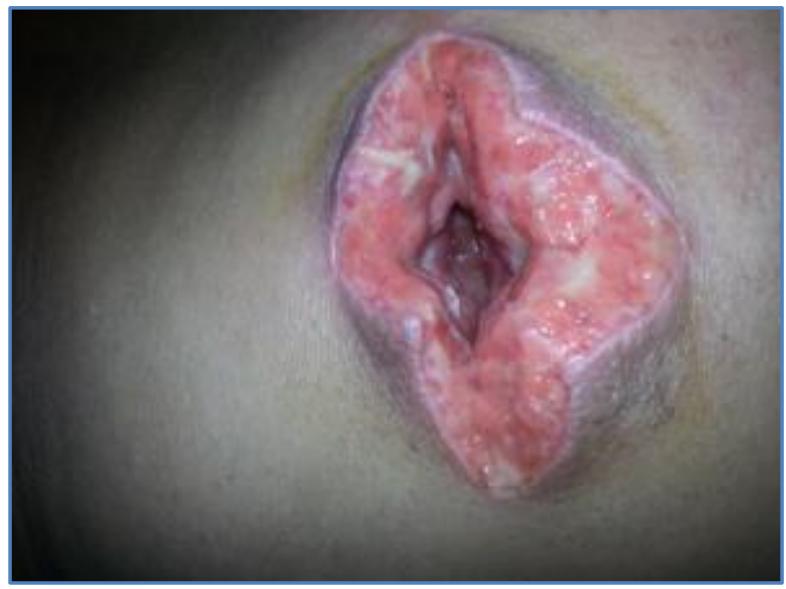

Fig. 1: Immediate Post-operative photograph

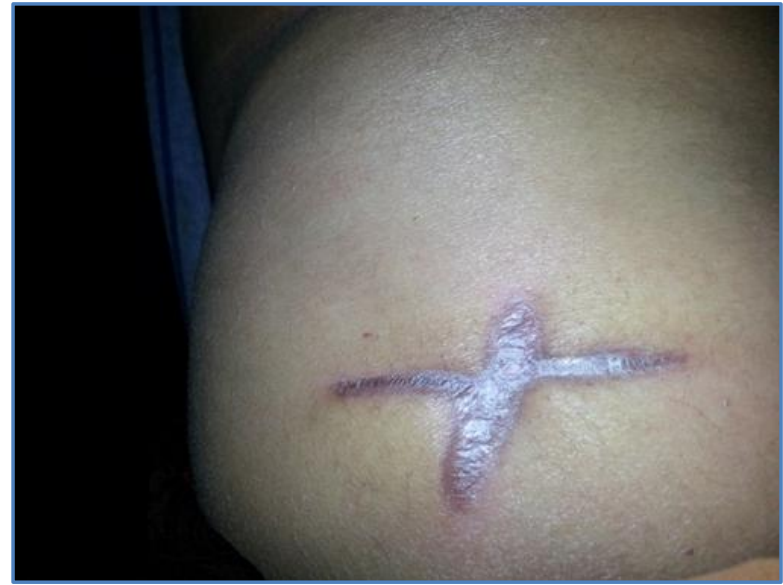

Fig. 2: Healed Scar

\section{AUTHORS:}

1. Girish Kullolli

2. Deepak R. Chavan

3. Shailesh Kannur

4. Bharat Shankar

5. Sachin Kadlewad

\section{PARTICULARS OF CONTRIBUTORS:}

1. Assistant Professor, Department of General Surgery, Shri B. M. Patil Medical College, Hospital and Research Center, Bijapur.

2. Assistant Professor, Department of General Surgery, Shri B. M. Patil Medical College, Hospital and Research Center, Bijapur.

3. Post Graduate, Department of General Surgery, Shri B. M. Patil Medical College, Hospital and Research Center, Bijapur.

4. Post Graduate, Department of General Surgery, Shri B. M. Patil Medical College, Hospital and Research Center, Bijapur.
5. Post Graduate, Department of General Surgery, Shri B. M. Patil Medical College, Hospital and Research Center, Bijapur

\section{NAME ADDRESS EMAIL ID OF THE CORRESPONDING AUTHOR:}

Dr. Bharat Shankar, Department of General Surgery, BLDEU's Shri B. M. Patil Medical College, Hospital and Research Center, Bangaramma Sajjan Campus, Bijapur - 586103.

E-mail: bharat.shankar@gmail.com

Date of Submission: 21/04/2014. Date of Peer Review: 22/04/2014. Date of Acceptance: 30/04/2014. Date of Publishing: 12/05/2014. 